\title{
CORROSION TESTS FOR REFRACTORY MATERIALS INTENDED FOR THE STEEL INDUSTRY - A REVIEW
}

\author{
${ }^{\#}$ CAMILLE REYNAERT*,**, EDYTA ŚNIEŻEK*, JACEK SZCZERBA* \\ *AGH University of Science and Technology, Faculty of Materials Science and Ceramics, \\ al. Mickiewicza 30, 30-59 Krakow, Poland \\ **Early Stage Researcher of the European Commission, Marie Sklodowska-Curie Actions Innovative Training Networks \\ in the frame of the project ATHOR - Advanced THermomechanical multiscale mOdelling of Refractory linings 764987 Grant \\ "E-mail: reynaert@agh.edu.pl
}

Submitted February 22, 2019; accepted February 24, 2020

\begin{abstract}
Keywords: Refractory/refractories, Corrosion testing, Steel industry, Slag, Molten steel, Static/Dynamic tests, Contact angle (wetting), Hot stage microscopy, Sessile drop test, Crucible test (cup test), Finger test (immersion test, dipping test), Rotating finger test, Induction furnace test, Rotary slag test, ATHOR, Review

The steel industry is one the biggest consumers of refractories. In this industry, refractories are commonly used as linings for steel production equipment, because they can sustain high temperature and corrosive attack in their working environment. However due to the harsh conditions, their life span is limited. Corrosion mainly by slag and molten steel is the principal phenomenon responsible for degradation and wear of the refractory bricks. It is a complex phenomenon that is due to infiltration (penetration) into and subsequent dissolution of the refractories by slags and molten steel. A thorough understanding of these mechanisms is necessary in order to improve the refractories behavior for steel making applications. However, even nowadays, no laboratory test can reproduce the real working conditions in the steel industry. According to the parameter of interest several testing methods have been developed. They can be static like the sessile drop test or crucible test or dynamic like the rotary slag test. This paper describes the principal corrosion tests used in the steel industry in order to give an overview of the way to determine and finally alleviate the impact of corrosion on refractories.
\end{abstract}

\section{INTRODUCTION}

Refractories are structural materials designed to be used in harsh environments. The definition of a refractory material according to the currently valid ISO standard is "non-metallic material or product (but not excluding those containing a proportion of metal) whose chemical and physical properties allow it to be used in a high temperature environment" [1]. In a broader sense, all structural materials that can be used in harsh environment and which retain most of their functionality when exposed to mechanical/thermomechanical strain and stresses, abrasion, corrosion/erosion as well as thermal shock can be considered as refractories. They can be found in applications such as glass furnaces, cement kilns, incinerators, blast furnaces and other hightemperature devices. They take different forms: pre-fired shapes such as bricks or unfired monolithic (usually castables) and can be made from various raw materials to fulfil the need of the different industries [2-4]. During their use, they degrade due to mechanical wear or chemical attack or a combination of both. The mechanical wear comes out from thermomechanical constrains - such as compression, tension, thermal shock - which make the refractory crack and break. The major chemical attack is corrosion, which comes from the interaction between a refractory and a corrosive medium: gas, molten metals, molten glasses, molten salts or slag. It results in a loss of mass and thickness and in the degradation of the material properties.

The steel industry is one of the major consumers of refractories. It was estimated in 2015 that 10 to $12 \mathrm{~kg}$ of refractories are necessary to produce 1 ton of steel in Europe and in America, $8 \mathrm{~kg}$ of refractories are necessary to produces 1 ton of steel in Japan and $30 \mathrm{~kg}$ of refractories are necessary to produces 1 ton of steel in China [5]. Indeed, the refractories degrade quickly and have to be replaced often due a combination of mechanical wear and chemical attack mainly by slags and to a lesser extent by molten steel. [3, 6-9]. The chemical attack which is corrosion is due to three mechanisms: infiltration (which some authors might prefer to call penetration) of slag or molten steel into the refractory, reaction with the latter and/or possibly its subsequent dissolution. Infiltration leads to the formation of an infiltrated region from the surface of the refractory brick which can promote spalling due to the difference of thermal the infiltrated region and the rest of the brick. Infiltration can also provoke the tearing out of aggregates. As for dissolution, it occurs because there is no chemical equilibrium at the interface between the refractories and the slag or molten steel. Dissolution can be direct (with the formation of a diffusion layer in the slag/steel at the interface between the brick and the slag/steel) or indirect 
(with the precipitation of new phases at the surface of the refractory brick). The former (direct) dissolution mode is usually faster and more aggressive than the latter (indirect). Infiltration and dissolution depend on different parameters such as wettability, temperature, slag composition etc. In order to determine the material behavior under corrosive attack and the influence of the relevant parameters several corrosion tests have been designed [10-11]. They can be static, which means that the slag/steel is not stirred, or dynamic, for which the brick or the slag/steel are put into motion.

The purpose of the present paper is to discuss, based on our own experience, the main research methods in the steel/slag corrosion of refractories.

\section{EXPERIMENTAL}

\section{Static tests}

Static tests are tests for which no agitation takes places, nor of the slag nor of the refractories. These tests will generally give lower corrosion rates compared to what is actually observed under working conditions. However, they are useful to study the chemical reactions that take place between the refractories and the corrosive medium.

\section{Hot stage microscopy}

A hot stage microscope, also called heating microscope, as shown in Figure 1, consists in a furnace with or without purging plug to control the atmosphere, a light source which lights up the inside of the furnace at low temperature, a camera opposite to the light source linked to a computer with [12] or without an integrated software for image treatment, a thermocouple the closest possible to the sample to control the temperature and optionally a filter added in front of the camera to reduce the effect of the sample's radiation at high temperature.

It can be used for several applications for refractories. The first one is the sessile drop test (which can also be performed using a goniometer at room temperature) which is designed to measure the contact angle between two phases including a solid and a liquid, as shown in Figure 2 where the Young equation can be applied (1) [13]:

$$
\gamma_{S V}=\gamma_{S L}+\gamma_{L V} \cos \theta
$$

where $\gamma_{S V}$ is the gas-solid surface tension, $\gamma_{L V}$ is the liquidgas surface tension, $\gamma_{S L}$ the liquid-solid surface tension, $\theta$ is the equilibrium contact angle. For refractories application the sessile drop test is used to follow the evolution of the contact angle as it can evolve with the temperature [12, 14-17] and composition [18-24].

Additionally, to the measurement of contact angle, this test can also be used for other applications such as the determination of the work of adhesion [25] but they will not be described here.

The second use of the hot stage microscope is the determination of the specific temperatures of the slag or steel [23] as shown in Figure 3. They are defined using the definition of to the standard DIN 51730:2007 [26] or ISO 540:2008 [27] for the determination of ashes fusibility of hard coal and coke:

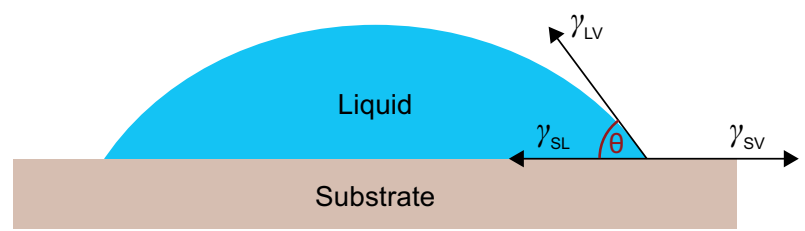

Figure 2. Schematic of a drop of liquid on a solid substrate.

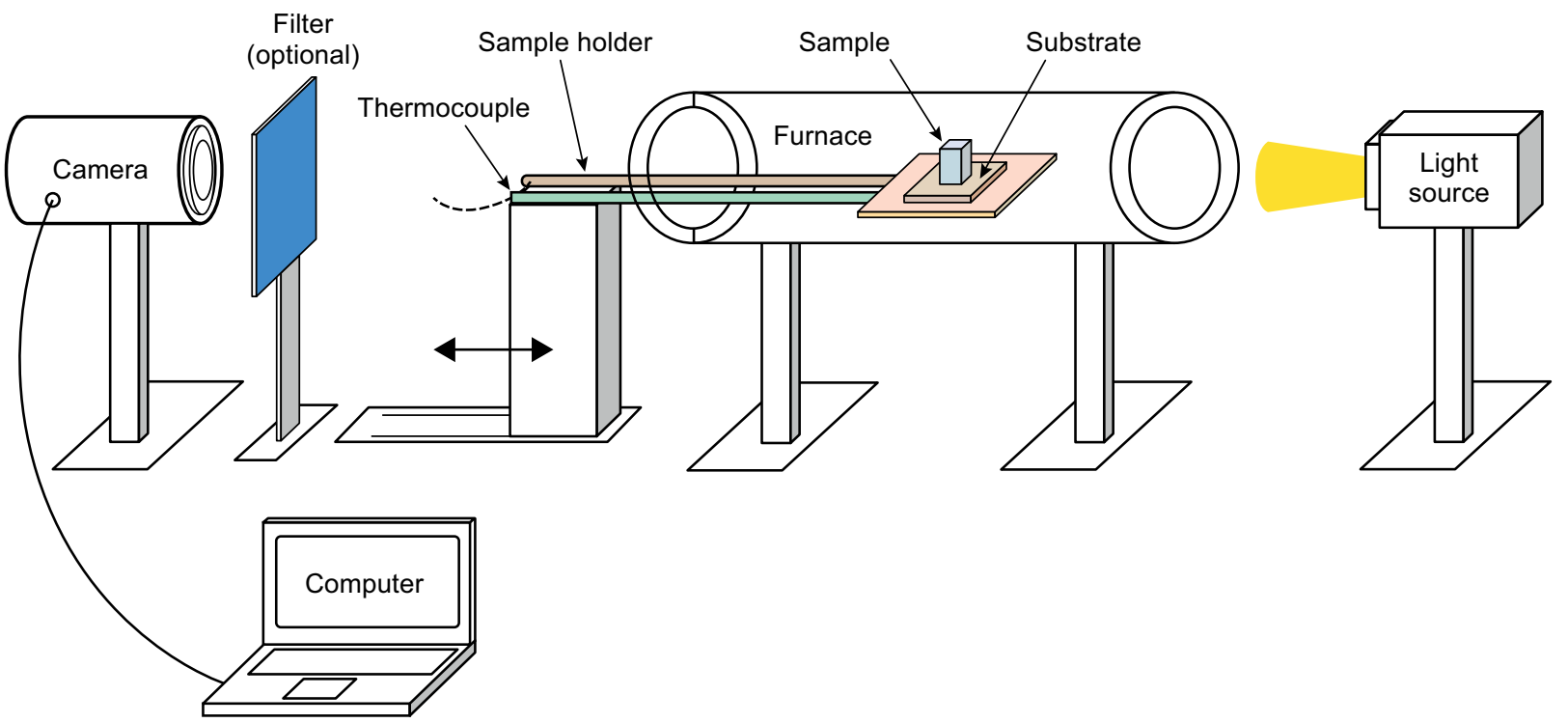

Figure 1. Schematic of a hot stage microscope. 


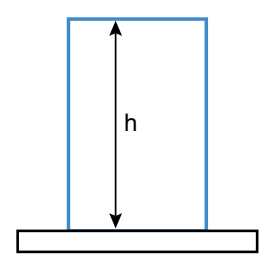

Initial sample
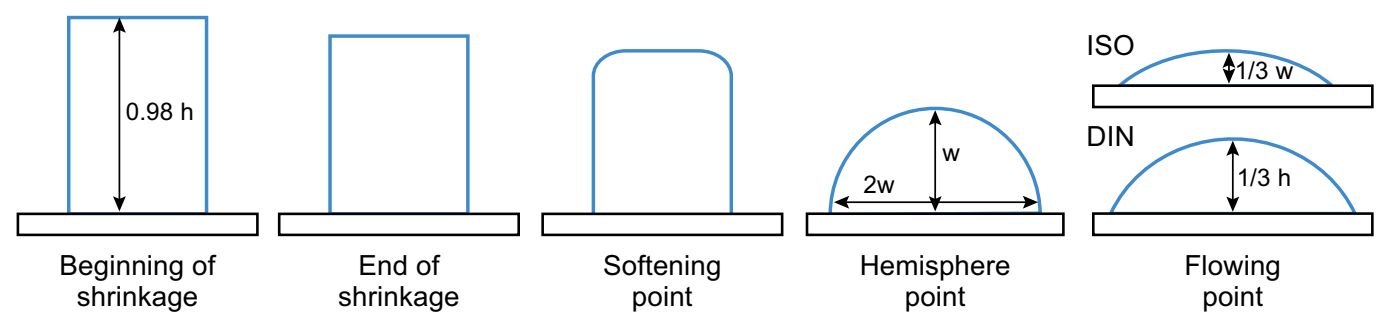

Figure 3. Schema of the appearance of hot stage microscopy sample for each specific temperature.

- Sintering temperature range (for powders only) - the range of temperature at which local melting takes place, preferentially at the particle contacts. This process leads to shrinkage of the sample while preserving its initial shape. The starting point is sometimes defined as the point where the sample height decrease to below $98 \%$ of the initial value.

- Softening point - temperature at which the first signs of sample softening, such as rounding of the edges or disappearance of the sample's asperity, are visible.

- Melting point or hemispherical point - temperature at which the shape of the test sample forms a spherical cap (depending on the contact angle), and the height of the sample is typically equal to half the length of its base or $2 / 3$ of the original height.

- Flowing point - temperature at which the sample spread out on the substrate to form a layer with a thickness of typically $1 / 3$ of the initial height (DIN 51730) or $1 / 3$ or the hemisphere point's height (ISO 540).

Hot stage microscopy can also be used for the characterization of behavior and observation of phenomena taking place in situ and determination of characteristic temperatures of a system: refractory material + corrosive agent. For this purpose, the components are mixed in a selected ratio.

To perform all the tests aforementioned, the first step is the preparation of the sample and, in case of determination or/and comparison of contact angle(s), the substrate. Indeed, the roughness of the surface of the substrate will have an influence on the contact angle. An increase of the subtract roughness will increase the contact angle as shown in Figure 4 [22]. The standard sample is a small bar or cylinder of a few $\mathrm{mm}^{3}$ but sample can be bigger. The ideal sample have straight and net edges, sharp angles, a base completely touching the substrate and should forms a $90^{\circ}$ angle with the substrate. The samples can be prepared in two ways. They can be

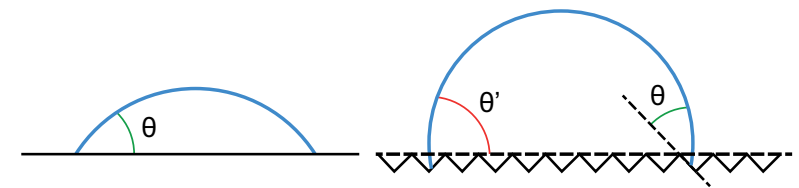

Figure 4. Schema of the effect of substrate porosity on the measure contact angle. cut using precision cutting tools for metal, otherwise samples have to be grind to a thin powder which is mixed with a small amount of liquid with or without binder, the paste obtained is then pressed in a mold of the desired shapes.

On the other hand, the substrates are prepared either by cutting a small piece out of a refractory or by preparing the substrates directly at the good dimension by split casting or pressing and firing. To achieve a smooth surface, the top face of the substrate can be grind and the roughness of the sample can be determined before the experiment $[15,21]$.

After preparation, the sample is put on the substrate, the ensemble is placed on the sample holder and is either inserted in the cold furnace and heated to the selected temperature at the selected heating rate, either inserted directly in the furnace at the selected temperature [18, 28]. The sample can be kept in the furnace during a dwell [24]. It can be cooled down with a controlled rate or not. The atmosphere can also be controlled by injecting the desired gas in the furnace.

During the heating cycle, the sample is recorded using a camera link to a computer and the information are extracted using an image analysis software either manually or automatically as programs have been developed to automatically treat the sample's images [12]. An example of sample evolution during heating is presented in Figure 5.

An example of the use of the hot stage microscope for the sessile drop test is the study of the wetting of coated alumina filter for the removal of inclusions by W. Yan et al. [21]. Different substrates consisting in heat treated pellets of pressed alumina powder coated with slurry containing various amount of carbon were prepared. Their roughness was measure after the heat treatment. A commercial steel, in the formed of cylinders of $10 \mathrm{~mm}$ in height and $10 \mathrm{~mm}$ in diameter, is used as the wetting medium for the experiment. During testing, the samples are heated at $10 \mathrm{~K} \cdot \mathrm{min}^{-1}$ up to $1500{ }^{\circ} \mathrm{C}, 1510^{\circ} \mathrm{C}$ or $1520{ }^{\circ} \mathrm{C}$ under argon atmosphere. At the selected temperature the sample are kept for $30 \mathrm{~min}$ and pictures are taken at regular time intervals $5 \mathrm{~min}$. The contact angles were then obtained from the picture, with a $1.5^{\circ}$ error, by image analysis using ImageJ software. The authors determined that the roughness of the substrate had a bigger effect on the contact angle than the carbon 


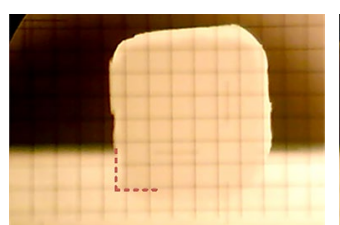

a) $100-1200^{\circ} \mathrm{C}$

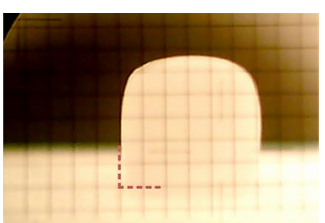

b) $1330{ }^{\circ} \mathrm{C}$

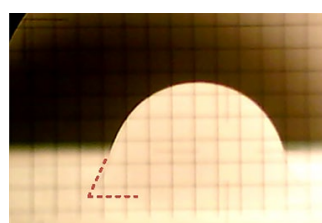

c) $1390{ }^{\circ} \mathrm{C}$

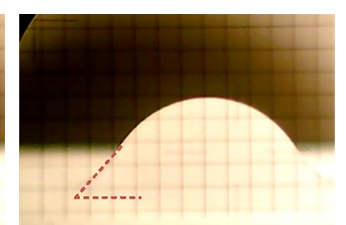

d) $1430{ }^{\circ} \mathrm{C}$

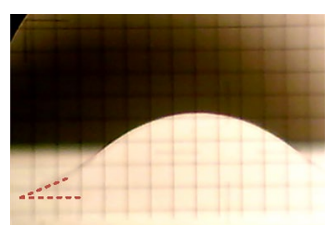

e) $1480{ }^{\circ} \mathrm{C}$

Figure 5. Evolution of the contact angle of a slag on an alumina substrate.

content of the coating. The contact angle evolves during the dwell time due to reaction and some special type of carbon (Nano-tube and Nano-sheets) favors its stabilizations by enabling reactions to take place at lower temperature.

Hot stage microscopy can provide a preliminary assessment of the corrosion resistance of the tested materials as well as information on contact angle and surface energy which cannot be obtained with the others testing methods. However, it has limitations because in the case of contact angle evolution, the slag is rapidly saturated by the dissolved refractory material, whereas in the real situation fresh slag constantly arrives and comes into contact with the refractories, the determination of the contact can be difficult and different values of angle can be found in literature for the same material, external conditions have a strong impact on the angle values.

Based on the principal of hot stage microscopy, improved tests have been developed such as the constrain sessile drop test [29], where the substrate imposed the size of the drop. This will change the angle between the liquid and the substrate and facilitates the measurement of the contact angle leading to lower error for the values. Another development is the sessile drop test where a drop of liquid is dropped on the substrate when the dwell temperature has been reached [28]. This test prevents solid state reactions between the substrate and the corrosive media before its melting. It might be of interest for the study of the evolution of contact angle according to the change of the liquid composition due to the dissolution of the substrate into the corrosive media.

\section{Crucible test}

The crucible test, also called cup test, is realized in hollow refractory samples as shown in Figure 6. They can be made by coring out refractory bricks or by

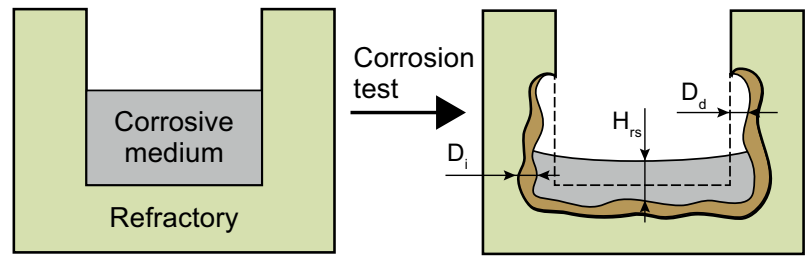

Figure 6. Schematic of crucible test; $D_{\mathrm{d}}$ is the dissolved brick thickness, $D_{\mathrm{i}}$ the infiltration depth and $H_{\mathrm{rs}}$ is the remaining slag level. shaping castables directly into a hollow cylinder shape. The tests can be performed either after drying or after heat treatment when using castable. The standard sample is a cylinder of $100 \mathrm{~mm}$ in outer diameter and $76 \mathrm{~mm}$ in total height cored out by a hole of $55 \mathrm{~mm}$ in inner diameter and a $55 \mathrm{~mm}$ in depth [11] but other sizes [30] and shapes [31] can also be used if attention is paid to the thickness of the walls and the bottom to avoid their complete infiltration.

For testing, the crucible is filled by the corrosive medium (slag, steel, steel topped by slag [32]) usually up to the middle of the hole. The crucible is heated up to the selected temperature for several hours. After the dwell, the samples can be quenched [32] or let to cool down naturally. The atmosphere can be controlled [30, 32]. At the end of the test, the crucible can be filled with resin to protect it and cut vertically. The two parts are studied to estimate the extent of degradation; a qualitative description of the general state of the sample can be done on the basis of visual inspection [11] (this classification is also applicable for all the following tests):

$\mathrm{U}$ : unaffected; for samples with no visible degradation, LA: lightly attacked; for samples with minor attack,

A: attacked; samples with clearly visible degradation, C: corroded; for completely corroded samples.

The formation of new phases can also be studied by sampling different areas of the crucible (cup) and analyze them by X-ray diffraction and SEM/EDS. Additionally, various parameters - such as dissolution or infiltration depth, mass loss, oxidation thickness - can be measured according to one variable - such as amount of a specific oxide in the slag, time, temperature - as shown in Figure 7 to determinate the impact this variable has on corrosion and/or compare the performance of the refractories. (This kind of comparison can be done for most of the tests presented below).

Examples of crucible tests can be found in the study by Benavidez et al. [33] on $\mathrm{MgO}-\mathrm{C}$ brick corrosion, where the performance of different bricks against corrosion and oxidation was compared. For this purpose, the authors prepared cups of $50 \mathrm{~mm}$ in edge length and $70 \mathrm{~mm}$ in height. In the middle of the sample, they drilled a hole of $20 \mathrm{~mm}$ in diameter and $30 \mathrm{~mm}$ in depth. Then they added $4 \mathrm{~g}$ of a high basicity slag (basicity $=6.7$ ) in each crucible hole, corresponding to approximately half of the hole height. After a firing for 2 hours in oxidizing atmosphere at $1650{ }^{\circ} \mathrm{C}$ the crucibles were filled with resin 
to avoid further damage and cut in half. The resistance of the refractory brick materials to oxidation was compared by measuring the thickness of the decarburized layer (average of 50 measurements taken along the wall of the crucible). Furthermore, optical and scanning electron microscopy were used to compare the materials' resistance to slag attack. The authors showed that the degradation of these refractory bricks was due to the infiltration of slag between the magnesia aggregates, the low dissolution of the aggregates and that the dissolution of the higher quality magnesia was slower than this of the lower quality magnesia.

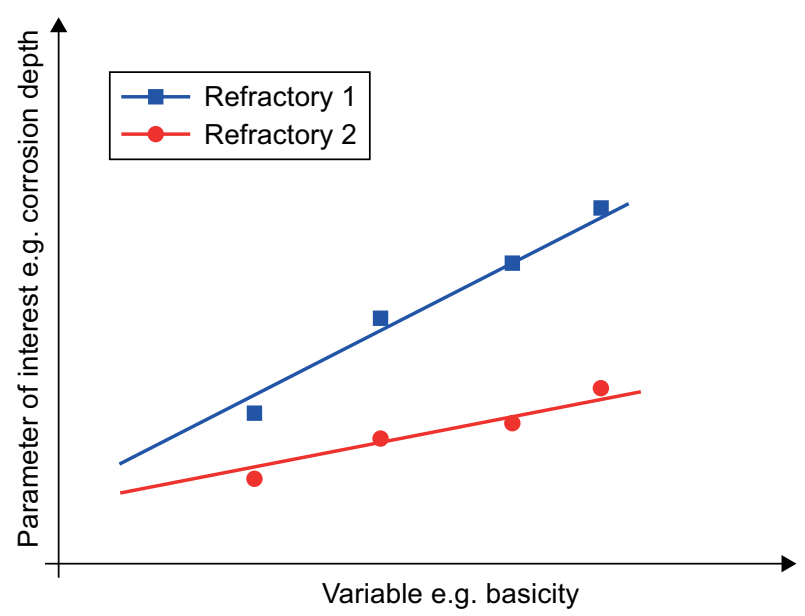

Figure 7. Example of evolution of corrosion depth with slag basicity for two refractories.

In the case of castables, the material can be cast directly in the crucible shape as in Luz et al. [34]. These authors investigated different compositions of aluminaspinel castable. They cast samples of $100 \mathrm{~mm}$ in outer diameter, $100 \mathrm{~mm}$ in total height and a hole of $50 \mathrm{~mm}$ in diameter and $50 \mathrm{~mm}$ in depth. Before the corrosion test, the samples were cured, dried, calcined at $800{ }^{\circ} \mathrm{C}$ for $8 \mathrm{~h}$ and heat treated at $1500{ }^{\circ} \mathrm{C}$ for $8 \mathrm{~h}$. After this, the samples were filled with $150 \mathrm{~g}$ of slag and corroded in oxidizing atmosphere for $2 \mathrm{~h}$ at $1500{ }^{\circ} \mathrm{C}$. After corrosion, the crucibles were cut in two halves and the wear and infiltration index was determined by the image analysis software ImageJ. The two indexes were defined as follows: the first index is obtained by dividing the distance between the initial internal surface and the one after corrosion $\left(D_{d}\right)$ by the overall wall thickness. The second one is the relative infiltrated area of the sample cross section, i.e. original and infiltrated areas of the sample cross section were measured and divided by each other to obtain the infiltration percentage. After polishing of the cross sections, phases were identified using SEMEDS. Additionally, thermodynamic simulations were realized using the software Factsage. The composition of the saturated slag after, corrosion obtained with XRD, served as an input for the software. They found out that changing the binder of the castable could improve its performance and they were able to predict the relative performance of the castables using thermodynamic simulations.

This test is often used because it is easy to perform, and several crucibles can be fired at the same time [30-36]. However, its use is limited because the slag quickly reaches saturation and is not stirred. Moreover, there is no thermal gradient inside the samples which generates a higher corrosion compare to the working conditions. Indeed, in working condition, the temperature decreases from the hot face to the cold face, consequently the viscosity of the liquid increases with the depth of infiltration which hinders the infiltration of the liquid

\section{Finger test}

The finger test, more precisely the static finger test, can also be called immersion or dipping test. It consists in immerging one or more cylinders (rods) [37] or prismatic refractory bars into a corrosive liquid (slag, steel, steel topped with slag [38]). The amount of liquid used for the experiment are depending on the experimenter but large amount of liquid compare to the sample size or liquid renewal during the experiment will help avoid the saturation of the corrosive liquid. The standard size of the samples is 10 to $30 \mathrm{~mm}$ in diameter (or cross-section edge length) and 50 to $120 \mathrm{~mm}$ in length [11] but samples with other dimensions are also use. A typical experimental device can be seen in Figure $8 \mathrm{a}$ and the typical evolution of sample shape during this test is indicated in Figure $8 \mathrm{~b}$.

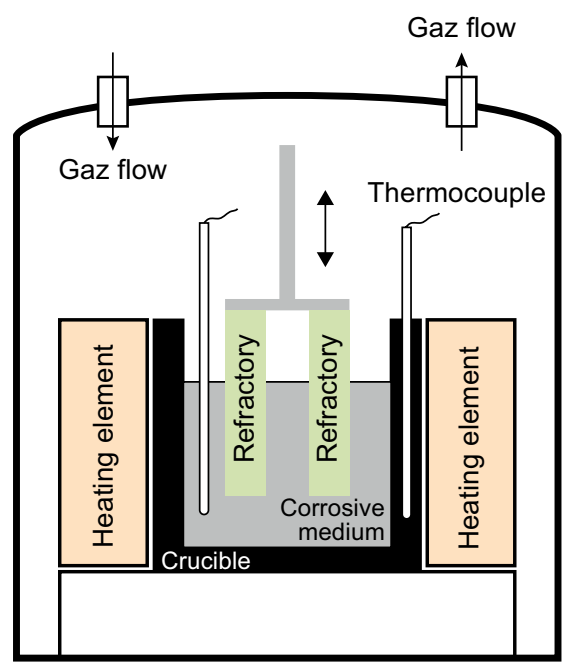

a)

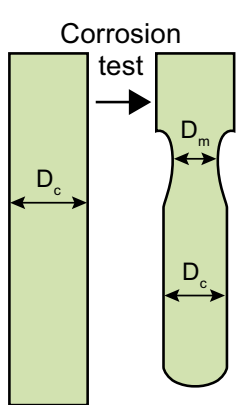

b)
Figure 8. Experimental settings that can be used for the finger test with control atmosphere (a), sample evolution during the finger test (b); $D_{i}$ corresponds to the original sample dimension in the transverse direction, $D_{m}$ to the dimension of the thinnest part (corrosion neck) and $D_{c}$ to the characteristic dimension of the corroded rod or bar in the transverse direction sufficiently far off the corrosion neck. 
To perform the experiments, the corrosive medium is heated up in a top loaded furnace to the selected temperature. The rods or bars are usually maintained above the crucible to heat them up before the dipping to avoid thermal shock $[23,39]$ then, they are dipped (by 30 to $70 \%$ of their length) into the molten liquid during a given amount of time. If the furnace is in a closed chamber the atmosphere can be controlled. When several samples are corroded at the same time, attention must be paid to avoid interactions between the samples which can be due to the change of composition of the corrosive liquid coming from the samples' dissolution.

After testing, the extent of degradation can be estimated by measuring the mass loss or thickness loss of the sample at the slag-air interface $\left(D_{m}\right)$ where the degradation is the highest due to the Marangoni effect and at mid-height of the bottom part of the sample $\left(D_{c}\right)$. These measurements can be used to compare the performance of corroded samples. They can also be used to obtain a rough approximation of the average corrosion rate (note that the corrosion rate is not uniform; it is faster at the beginning of the experiment - no diffusion layer has built up at the refractory surface and the slag is not saturated - and decreases progressively during the test). The infiltration depth can be measured in addition to the thickness loss when the sample is cut vertically. By sampling the rod or bar, it is possible to obtain the composition, phases and morphology of the different areas (interface and infiltrated zone) using XRD and SEM with EDS.

The finger test has several advantages: it is relatively easy to realize and in some cases several samples can be tested at the same time. The temperature and atmosphere, in an enclosed chamber, are controlled. The samples are inserted in molten slag or steel, which prevents solid state reaction before the corrosion, on the contrary of the hot stage microscope and the cup test. However, the finger test needs more slag or other corrosive medium than the hot stage microscope and the cup test. When the quantity of slag is not large enough, the slag will be saturated. The absence of a thermal gradient inside

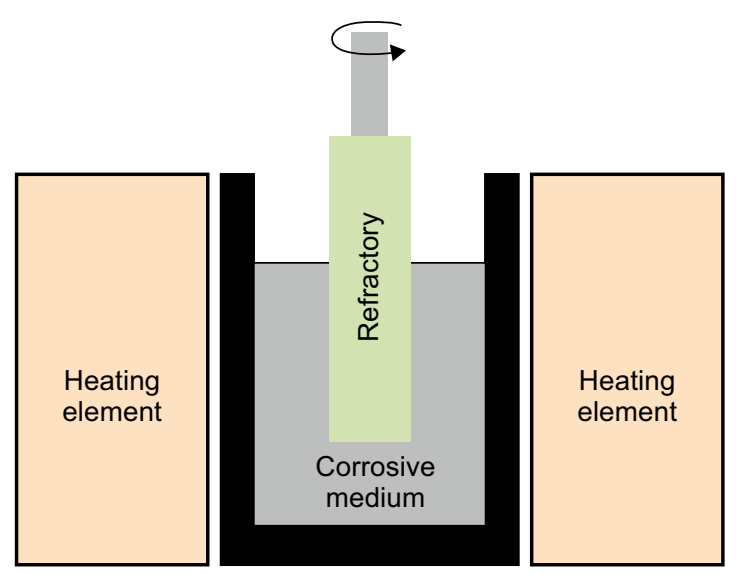

Figure 9. Schematic of a rotating finger test. the sample leads to a higher corrosion. Furthermore, the corrosive media is not stirred which is not representative of the real situation. To improve this test, the rotating finger test was developed and is nowadays more often used than the static finger test.

\section{Dynamic tests}

Dynamic tests are corrosion tests for which the corrosive liquid or the refractories are stirred. The experimental conditions are usually closer to the real industrial operating conditions compared to static test, but the experiments are more difficult to realize.

\section{Rotating finger test}

The rotating finger test is very similar to the static finger test, but in order to be closer to the working conditions, the rods are rotated inside the slag/steel with a defined angular speed [10]. A typical device with controlled atmosphere can be seen in Figure 9.

In case of the rotating finger test, a static diffusion layer is not established, in this case, the corrosion rate can be expressed using the following equation type (6) [40]:

$$
-\frac{d r}{d t}=A_{0} U^{\mathrm{b}}
$$

where $A_{0}$ is a constant, $U$ is the rotating cylinder peripheral velocity, $r$ is the rotating cylinder radius, $t$ is the time and $b$ is a constant. The term can be used to calculate the mass transfer of the different species into the corrosive liquid. In addition to the dissolution of the refractory into the slag, erosion can take place: the matrix or the grains can be torn off by the flow of the corrosive liquid. All together the corrosion rate is higher with the rotating finger test compared to the static finger test.

According to the literature, the static finger test is less frequently used than the rotating finger test $[37,38$, 41-44]. That is why only examples of the latter are given here. Jansson et al. [40] studied the corrosion resistance of three doloma-based refractories: doloma, doloma-C and doloma-magnesia using three different alumina-rich slags. 41 experiments were conducted using the rotating finger test under argon atmosphere. For each test, $60 \mathrm{~g}$ of slag was melted in carbon crucibles and rod of refractory of $13 \mathrm{~mm}$ in diameter were dipped when the selected temperature was reached. For each experiment, one parameter was modified: either the rotation speed from 100 to $400 \mathrm{rpm}$, either the immersion time from 15 to $120 \mathrm{~min}$, either temperature from 1500 to $1700{ }^{\circ} \mathrm{C}$. Some experiments were realized twice to verify the test repeatability. After testing, the authors calculated the thickness loss to determinate the average reaction rate. It turned out that the changes of condition had more or less impact on the different types of bricks. For example, the doloma brick was more affected by the increase of rotation speed than the two other types of bricks. 
Another example is the study realized by Jeon et al. [45]. They investigated two high-spinel refractories containing the same amount of spinel but made using two different binders. Rods of $18.5 \mathrm{~mm}$ in diameter of were immerged in $100 \mathrm{~g}$ of a high-MnO-content slag and their resistance to corrosion was tested at $1550{ }^{\circ} \mathrm{C}$ with a rotation speed of $150 \mathrm{rpm}$ and different immersion times (30,60 and $120 \mathrm{~min}$ ). After testing the authors compared the thickness loss of the samples and investigated the difference in phase composition using SEM and XRD. They found out that due to the difference of binder, the two refractories were different from the viewpoint of porosity which led to a difference in behavior: one sample suffered thickness loss and the other one had its bottom part torn off, the first sample had a denser binding phase while the second one was more porous. Hence, the authors explained the difference in behavior by a deeper slag infiltration in the second sample, which led to its weakening and breaking under the flow of slag.

This test has similar advantages and disadvantages to the static rotating finger test, the main difference being the flow of the corrosive liquid.

\section{Induction furnace test}

The induction furnace test is a semi-static test. It consists of heating steel [46], topped or not with slag [47], by induction. For this test, refractories are shaped to form a crucible with polygonal surface, as shown in Figure 10a $[10,11]$. The standard dimensions are $220 \mathrm{~mm}$ in width and $250 \mathrm{~mm}$ in height. It can be made of bricks, castables [48] or bricks embedded in castables [49]. Different compositions can be tested in the same crucible to unsure the same corrosion condition, but in such a case attention must be paid to the compatibility between the refractories. The standard amount [11] of material used for this test is $15 \mathrm{~kg}$ of steel and if slag is added, 1 to $2 \mathrm{~kg}$ of slag - renewable to keep the slag compositions constant [50] - but these quantities can vary $[48,49]$.

In order to perform this test, the crucible is installed in an induction furnace as shown in Figure 10b, steel is

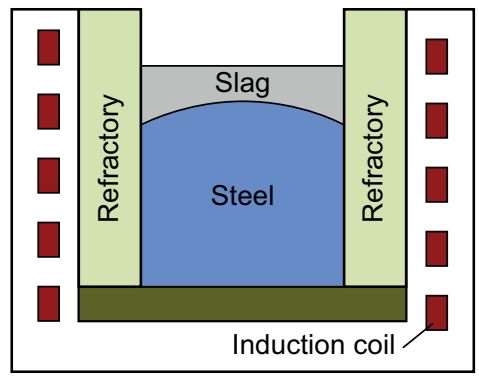

a)

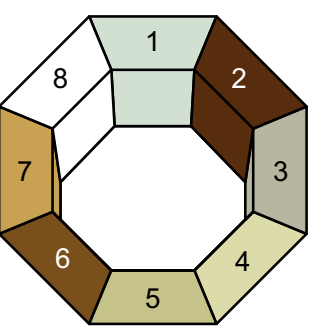

b)
Figure 10. Induction furnace (here without controlled atmosphere) (a) and Octagonal (8-faced) crucible made by different refractories used in the induction furnace test (b). introduced in the crucible and heated up by induction to the selected temperature which can be controlled with a thermocouple either inserted in the wall of the crucible either immerged in the steel [51]. When the steel is molten and the appropriate temperature is reached, slag can be added on top on the steel. Often the slag cannot be heated up by induction, its heating is achieved thanks to the contact with hot steel. The corrosive liquid is left to react with the refractories for the desired time. Due to the heating mode, steel is naturally stirred - according to the frequency used for the induction heating, the flow of the molten steel is more or less strong. Furthermore, gases can be blown above the surface of the liquid to reproduce more closely the working atmosphere [51] or the atmosphere can be controlled if the furnace is operated in a closed chamber. At the end of experiment, the whole experimental setup can be cooled down together or the crucible can be emptied and cooled down empty [49] or else a gas can be blown onto the surface to quench the corrosive liquid [52].

After the test the extent of degradation is estimated by visual inspection or by measuring thickness and infiltration loss of the refractories as shown in Figure 11. If bricks are corroded under the same conditions, it is possible to compare the measurements to evaluate their relative performance [11].

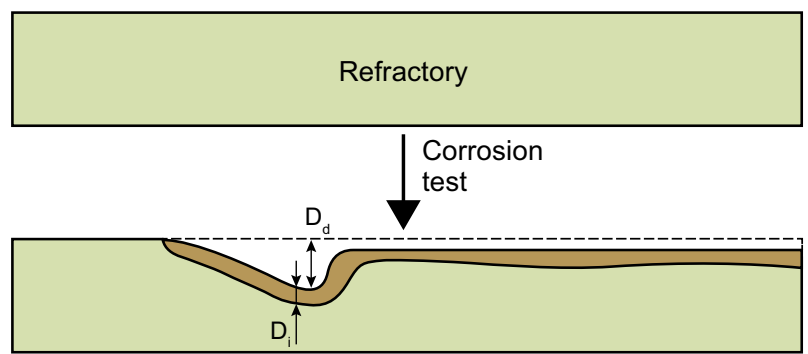

Figure 11. Induction furnace corrosion test - sample evolution with $D_{d}$ the greatest dissolution depth and $D_{i}$ the (average) infiltration depth.

Many papers using this test can be found in the literature. A practical example is given by Zou et al. [50] who compared the resistance to corrosion of aluminamagnesia castables using a $\mathrm{CaO}-\mathrm{SiO}_{2}-\mathrm{Al}_{2} \mathrm{O}_{3}$ synthetic slag. Four different castables were tested. Their matrix was identical but their aggregates were different: one contained dense tabular corundum with small and large pores, one contained light-weight corundum with only large pores and the two others contained light-weight corundum with only small pores. The four castables were cast in rectangular molds of dimensions $25 \times 25 \times$ $\times 125 \mathrm{~mm}$ on a vibrating table, then they were cured, dried and finally, they were installed in a medium range induction furnace $(3500 \mathrm{~Hz}) .2 .7 \mathrm{~kg}$ of steel were placed inside the crucible and heated up to $1600-1625{ }^{\circ} \mathrm{C}$. When this temperature was reached, $70 \mathrm{~g}$ of slag was 
added on top of the steel. The experiment was carried out for $40 \mathrm{~min}$ and at the end, the liquids were poured out and the empty crucible was left to cool down naturally. After the experiment the authors compared the four corroded samples visually and they found out that the samples with low porosity and light-weight aggregates had the best resistance to corrosion.

This test has advantages, the temperature and the atmosphere can be controlled. Due to the heating by induction a thermal gradient is established: the internal face of the brick is heated by the steel and the external face of the brick is in a cold zone. Furthermore, this mode of heating generates a stirring of the steel and consequently, a stirring of the slag; this leads to the destruction of the diffusion layer and so, to the increase of the corrosion rate - this situation is closer to the working conditions. Finally, the reproduction of the interface steel/slag is interesting as it mimics the working conditions, especially the Marangoni effect which provokes a local increase of the wear of the brick. However, this test has drawbacks: the slag can be saturated and the stirring of the steel melt and the slag is by far not as strong as in real steelmaking equipment.

\section{Rotary slag test}

The rotary slag test is a dynamic test where solid slag and/or steel is introduced in a cylindrical chamber and melted with a burner as shown in Figure 12a. The cylindrical chamber is lined with refractory bricks to create a chamber with 6 to 12 faces as shown in Figure $12 \mathrm{~b}$. This crucible can be made either by machining samples either by casting samples directly in the chamber. For castables, they can be tested in green state or in the fired state. If different samples are tested at the same time, attention should be paid to their compatibility and comparable corrosion rates, otherwise the corrosion of neighboring samples could be affected $[10,11]$.

To conduct this test, the chamber is rotated horizontally at a low speed (from 2 to $6 \mathrm{rpm}$ ). Solid slag, sometimes with steel [53], in the form of fine powder or small pellets, is introduced into the cold chamber [54] or into the chamber at the selected temperature [53, 55-57]. A burner, often fueled by propane and oxygen, is placed inside the chamber to heat it. As the temperature inside the chamber depends on the flow of fuel in the burner, the temperature is measured at given intervals of time with a pyrometer to help adjust the flow.

At regular intervals, the slag can be changed [56, $58,59]$ : the chamber is tilted vertically to empty out the slag then it is tilted back to the horizontal position and fresh slag is introduced again. The contact time for each batch, as well as the number of cycles, are the experimenter's choice. In some cases, between two cycles a less aggressive slag can be introduced into the chamber in order to "clean" the refractories and insure that only fresh slag is present for the new cycle. The behavior of the refractories under thermal shock can also be tested by blowing cold gas into the furnace just after emptying it and bringing it back to the horizontal position [53-55]. After testing, the samples can be examined by visual inspection, and the dissolution and infiltration of the samples can be compared in relative terms if they are tested together; the phases and the composition can be analyzed using XRD and SEM-EDS.

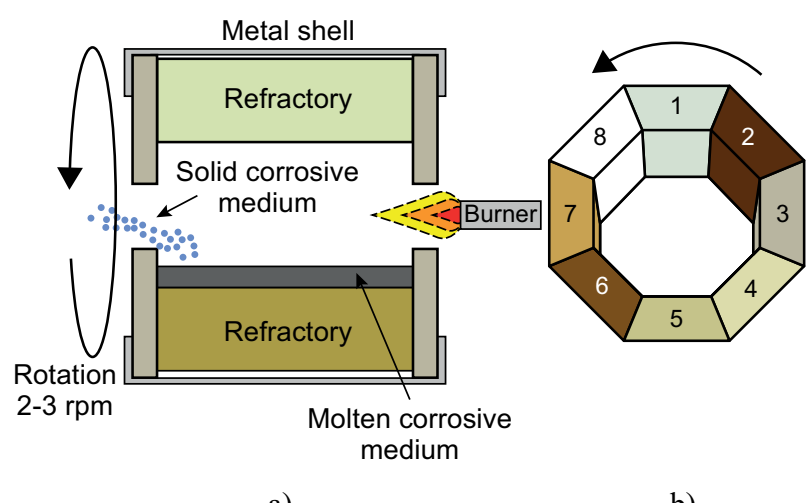

a)

b)

Figure 12. Rotating furnace (a) and crucible with 8 faces used in the rotating furnace (b).

Paper using this tests are less numerous than for other tests. In Ko's [55] work, the corrosion of several alumina castables containing spinels with different amounts of $\mathrm{MgO}$ were studied using the rotary slag test with steel and slag. The test consisted of 6 consecutive cycles with addition of steel followed by addition of slag in the hot chamber. For each cycle, the rotation speed was $2 \mathrm{rpm}$, and steel and slag were hold at $1650{ }^{\circ} \mathrm{C}$ for $60 \mathrm{~min}$. At the end of each cycle, the chamber was emptied and new steel and slag were added for the next cycle. After the sixth cycles, the chamber was emptied and let to cool down naturally, then the bricks were removed. The authors compared the dissolution and infiltration of the bricks by visual inspection. They defined the extent of dissolution according to the parameter $D(7)$ :

$D=\underline{\text { thickness of sample before corrosion test }- \text { thickness of sample after corrosion test }}$ thickness of sample before corrosion test

they calculated the infiltration in the same way by using the thickness of the sample after the corrosion test and the thickness of the reaction area zone. They found out that the samples containing spinel with a high $\mathrm{MgO}$ content had a higher resistance to corrosion. They also stated that the dissolution of spinel and the precipitation of $\mathrm{MgO}$ in the slag increased the viscosity of the slag and hence, decreased the infiltration depth of the slag.

This rotary slag test has several advantages: the slag/ steel cannot reach saturation if it is refreshed regularly in sufficiently short intervals, the slag/steel is stirred and there is a thermal gradient inside the brick due to the heating at center of the chamber. However, this test has 
also several disadvantages: the temperature is difficult to control, the refractories can interact between themselves, and the test reproducibility is low. Furthermore, it is not easy to realize and requires big quantities of slag (at least several hundred of grams).

Other tests can be and have been designed to improve the existent or afore mentioned ones or to study the test reproducibility under specific conditions, but they are not described here, because they are not as broadly used as the ones presented.

\section{CONCLUSION}

The main corrosion tests used in the steel industry have been presented and critically reviewed in this paper. They can be used either for a qualitative comparison of the corrosion and infiltration of the samples with an optical classification based on visual inspection (U, LA, A, C) either for a quantitative analysis when composition and phases are analyzed mainly by XRD and SEM-EDS. Of course, according to the parameter of interest and the equipment available, one or another test will be favored. For example, the sessile drop test is the only suitable method to study the interfacial tension, crucible or cup tests can be used to study the impact of the change of composition of the corrosive liquid or to quickly compare the resistance of several materials using the same slag/ steel and the rotary slag tests can be used to reproduce conditions closer to reality, but it is more complicated to realize and it needs more corrosive liquid and more refractory material (bricks).

In order to compare the different tests and as a handy reference for the reader, Table 1 summarizes the advantages and disadvantages of each test.
Acknowledgement

The work was partially supported by statutory founds of the Faculty of Material Science and Ceramics, AGH University of Science and Technology, Krakow, Poland and the Marie Sktodowska-Curie Actions Innovative Training Networks in the frame of the project ATHOR - Advanced THermomechanical multiscale $\mathrm{mO}$ delling of Refractory linings 764987 Grant.

\section{REFERENCES}

1. ISO 836 (2001) (en). Terminologies for refractories.

2. Szczerba J. (2006): Klasyfikacja materiałów ogniotrwałych według zunifikowanych norm europejskich. Materiaty Ceramiczne/Ceramic Materials, 58, 6-16.

3. Schacht C. (2004). Refractories Handbook. Marcel Dekker Inc., New York - Besel.

4. Routschka G., Hamersley L. M., Hamersley J. (2004). Pocket Manual Refractory Materials: Basics, Structures, Properties. $2^{\text {nd }}$ ed. Essen: Vulkan-Verlag.

5. Horckmans L., Nielsen P., et al. (2019): Recycling of refractory bricks used in basic steelmaking: A review. Resources, Conservation and Recycling, 180, 297-304. doi: 10.1016/j.resconrec.2018.09.025

6. Lee W., Zhang S. (1999): Melt corrosion of oxide and oxide-carbon. International Materials Reviews, 44, 3, 77-104. doi: 10.1179/095066099101528234

7. Poirier J., Lefort P., Valette S. (2011) : Corrosion des céramiques. Techniques de l'ingénieur [Online]. Available: https://www.techniques-ingenieur.fr/base-documentaire/ materiaux-th $11 /$ materiaux-resistance-a-la-corrosion-etau-vieillissement-42373210/corrosion-des-ceramiquescor401/

8. Reynaert C., Śnieżek E., Szczerba J. (2018): The main aspects of refractory materials corrosion in steel production equipment. Materiaty Ceramiczne/Ceramic Materials, 70, 174-185.

Table 1. Corrosion tests parameters comparison.

\begin{tabular}{lcccccc}
\hline & $\begin{array}{c}\text { Sessile drop } \\
\text { test }\end{array}$ & Crucible test & Finger test & $\begin{array}{c}\text { Rotating } \\
\text { finger test }\end{array}$ & $\begin{array}{c}\text { Induction } \\
\text { furnace }\end{array}$ & $\begin{array}{c}\text { Rotary slag } \\
\text { test }\end{array}$ \\
\hline Thermal gradient & No & No & No & No & Yes & Yes \\
\hline Slag volume & Small & Small & Big & Big & Medium & Medium \\
\hline Slag renewal & No & No & Possible & Possible & Possible & Yes \\
\hline Interaction between brick & No & No & Possible & Possible & Possible & Possible \\
\hline Temperature control & Good & Good & Good & Good & Good & Difficult \\
\hline Atmosphere control & Possible & Possible & Possible & Possible & Possible & Impossible \\
\hline Slag agitation & No & No & No & Strong & Medium & Strong \\
\hline $\begin{array}{l}\text { Possibility to test the thermal } \\
\text { shock resistance }\end{array}$ & No & No & Yes & Yes & No & Yes \\
\hline Easy to realize & Very easy & Very easy & Easy & Easy & Difficult & Difficult \\
\hline Cost & Very cheap & Cheap & $\begin{array}{c}\text { Average to } \\
\text { expensive }\end{array}$ & $\begin{array}{c}\text { Average to } \\
\text { expensive }\end{array}$ & $\begin{array}{c}\text { Average to } \\
\text { expensive }\end{array}$ & Expensive \\
\hline Scale & Low & Low & Medium & Medium & High & High \\
\hline
\end{tabular}


9. McCauley R. A. (2004). Corrosion of Ceramic and Composite Materials. $2^{\text {nd }}$ edition. Marcel Dekker Inc., New York - Besel.

10. Mattione A., Smith J. and O'Malley R. (2016): Review of slag line corrosion testing methods. In: Proceeding of $53^{\text {rd }}$ Annual Symposium on Refractories, St Louis, Missouri.

11. CEN/TS 15418 (2006) (en). Methods of test for dense refractory products - Guidelines for testing the corrosion of refractories caused by liquids.

12. Panna W., Wyszomirski P., Kohut P. (2016): Application of hot-stage microscopy to evaluating sample morphology changes on heating. Journal of Thermal Analysis and Calorimetry, 125, 1053-1059. doi: 10.1007/s10973-0165323-Z

13. Zisman W. A. (1964): Relation of the equilibrium contact angle to liquid and solid constitution. Advances in Chemistry, 43, 1-51. doi: 10.1021/ba-1964-0043.ch001

14. Boccaccini A. R., Hamann B. (1999): Review in situ hightemperature optical microscopy. Journal of Materials Science, 34, 5419-5436. doi: 10.1023/A:1004706922530

15. Shen P., Zhang L. et al. (2016): Wettability between molten slag and dolomitic refractory. Ceramics International, 42, 16040-16048. doi: 10.1016/j.ceramint.2016.07.113

16. Shen P., Zhang L., et al. (2017): Wettability between Fe-Al alloy and sintered $\mathrm{MgO}$. Ceramics International, 43, 7674 7681. doi: 10.1016/j.ceramint.2017.03.067

17. Aneziris C. G., Hampel M. (2008): Microstructured and electro-assisted high-temperature wettability of $\mathrm{MgO}$ in contact with a silicate slag-based on fayalite. Applied Ceramic Technology, 5, 469-479. doi: 10.1111/j.1744-7402. 2008.02223.x

18. Liu Z., Yuan L., Jin E. et al. (2019): Wetting, spreading and corrosion behavior of molten slag on dense $\mathrm{MgO}$ and $\mathrm{MgO}-\mathrm{C}$ refractory. Ceramics International, 45, 718-724. doi: 10.1016/j.ceramint.2018.09.234

19. Burzacchini B. (1996). Use of the hot stage microscope to evaluate the characteristics and behaviour of frits and glazes at different heating rates. Qualicer, Castellon.

20. Ellefson B. S., Taylor N. W. (1938): Surface properties of fused salts and glasses: I Sessile-drop method for determining surface tension and density of viscous liquids at high-temperatures. Journal of the American Ceramic Society, 21, 193-205. doi: 10.1111/j.1151-2916.1938. tb15764.x

21. Yan W., Schmidt A., et al. (2018): Wettability phenomena of molten steel in contact with alumina substrates with alumina and alumina-carbon coatings. Journal of the European Ceramic Society, 38, 2164-2178. doi: 10.1016/j. jeurceramsoc.2017.12.001

22. Schuster J. M., Schvezov C. E., Rosenberger M. R. (2015): Influence of experimental variables on the measure of contact angle in metals using the sessile drop method. Procedia Materials Science, 8, 742-751. doi: 10.1016/j. mspro.2015.04.131

23. Park J. H., Suk M. O., et al. (2010): Interfacial reaction between refractory materials and metallurgical slags containing fluoride. Steel research International, 81, 10, 860-868. doi: 10.1002/srin.201000157

24. Jankovsky O., Storti E., et al. (2018): Unique wettability phenomenon of carbon-bonded alumina with advanced nanocoating. Applied Materials Today, 13, 24-31. doi: 10.1016/j.apmt.2018.08.002

25. Verein Deutscher Eisenhüttenleute (1995). Slag atlas. 2nd ed. Verlag Stahleeisen, Düsseldorf.
26. DIN 51730 (2007) (en). Prüfung fester brennstoffe bestimmung des asche-schmelzverhaltens (Testing of solid fuels - Determination of fusibility of fuel ash).

27. ISO 540 (2008) (en). Hard coal and coke - Determination of ash fusibility.

28. Heo S.-H., Lee K., Chung Y. (2012): Reactive wetting phenomena of $\mathrm{MgO}-\mathrm{Crefractories} \mathrm{in} \mathrm{contact} \mathrm{with} \mathrm{CaO}-\mathrm{SiO}_{2}$ slag. Transactions of Nonferrous Metals Society of China, 22, 870-875. doi: 10.1016/S1003-6326(12)61818-4

29. Duchesne M. A., Hughes R. W. (2017): Slag density and surface tension measurements by the constrained sessile drop method. Fuel, 188, 173-181. doi: 10.1016/j.fuel. 2016.10.023

30. Braulio M., Luz A., et al. (2011): Basic slag attack of spinelcontaining refractory castables. Ceramics International, 37, 1935-1945. doi: 10.1016/j.ceramint.2011.02.007

31. Hemberger Y., Berthold C., Nickel K. G. (2012): Wetting and corrosion of yttria stabilized zirconia by molten slags. Journal of the European Ceramic Society, 32, 2859-2866. doi: 10.1016/j.jeurceramsoc.2011.12.005

32. Tang H., Wu G., et al. (2017): Comparative evaluation investigation of slag corrosion on $\mathrm{Al}_{2} \mathrm{O}_{3}$ and $\mathrm{MgO}$ $\mathrm{Al}_{2} \mathrm{O}_{3}$ refractories via experiments and thermodynamic simulations. Ceramics International, 43, 16502-16511. doi: 10.1016/j.ceramint.2017.09.034

33. Benavidez E., Brandaleze E., et al. (2015): Corrosion study of $\mathrm{MgO}-\mathrm{C}$ bricks in contact with a steelmaking slag. Procedia Materials Science, 8, 228-235. doi: 10.1016/j. mspro.2015.04.068

34. Luz A., Braulio M., et al. (2012): Slag attack evaluation of in situ spinel-containing refractory castables via experimental tests and thermodynamic simulations. Ceramics International, 38, 1497-1505. doi: 10.1016/j.ceramint.2011. 09.033

35. Chen J., Li N., Yan W. (2016): Influence of $\mathrm{Ti}_{3} \mathrm{AlC}_{2}$ on corrosion resistance and microstructure of $\mathrm{Al}_{2} \mathrm{O}_{3}-$ $-\mathrm{Ti}_{3} \mathrm{AlC}_{2}-\mathrm{C}$ refractories in contact with ladle slag. Journal of the European Ceramic Society, 36, 1505-1511. doi: 10.1016/j.jeurceramsoc.2015.12.037

36. Sako E. Y., Braulio M., Pandolfelli V. C. (2012): The corrosion resistance of microsilica-containing $\mathrm{Al}_{2} \mathrm{O}_{3}-\mathrm{MgO}$ and $\mathrm{Al}_{2} \mathrm{O}_{3}$-spinel castables. Ceramics International, 38, 4783-4789. doi: 10.1016/j.ceramint.2012.02.066

37. Baudin C., Criado C., et al. (2011): Dynamic corrosion of $\mathrm{Al}_{2} \mathrm{O} 3-\mathrm{ZrO}_{2}-\mathrm{SiO}_{2}$ and $\mathrm{Cr}_{2} \mathrm{O}_{3}$-containing refractories by molten frits. Part I: Macroscopic analysis. Journal of the European Ceramic Society, 31, 697-703. doi: 10.1016/j. jeurceramsoc.2010.11.023

38. Guo M., Jones P. T., et al. (2006): Degradation mechanisms of magnesia-chromite refractories by high-alumina stainless steel slags under vacuum conditions. Journal of the European Ceramic Society, 26, 3831-3843. doi: 10.1016/j. jeurceramsoc. 2005.12.025

39. Cho M.-K., Van Ende M.-A., et al. (2012): Investigation of slag-refractory interactions for the Ruhrstahl Heraeus (RH) vacuum degassing process in steelmaking. Journal of the European Ceramic Society, 32, 1503-1517. doi: 10.1016/j. jeurceramsoc.2012.01.005

40. Jansson J., Brabie V., Jönsson P. (2008): Corrosion mechanism of commercial doloma refractories in contact with $\mathrm{CaO}-\mathrm{Al}_{2} \mathrm{O}_{3}-\mathrm{SiO}_{2}-\mathrm{MgO}$ slag. Ironmaking and Steelmaking, 35, 99-107. doi: 10.1179/030192307X231595 
41. Chen L., Malfliet A., at al. (2016): Degradation mechanisms of alumina-silica runner refractories by carbon steel during ingot casting process. Ceramics International, 42, 10209-10214. doi: 10.1016/j.ceramint.2016.03.139

42. Um H., Lee K., et al. (2014): Effect of carbon content of ferromanganese alloy on corrosion behaviour of $\mathrm{MgO}-\mathrm{C}$ refractory. Ironmaking and Steelmaking, 41, 31-37. doi: 10.1179/1743281212Y.0000000098

43. Guo M., Parada S., et al. (2004): Laboratory study of the interaction mechanisms between magnesia-chromite refractories and $\mathrm{Al}_{2} \mathrm{O}_{3}$-rich VOD slags. In: Proceedings of VII International Conference on Molten Slags Fluxes and Salts, Cap Town, pp. 327-336.

44. Guo M., Parada S., et al. (2007): Degradation mechanisms of magnesia-carbon refractories by high-alumina stainless steel slags under vacuum. Ceramics International, 33, 1007-1018. doi: 10.1016/j.ceramint.2006.03.009

45. Jeon J., Kang Y., et al. (2017): Corrosion-erosion behavior of $\mathrm{MgAl}_{2} \mathrm{O}_{4}$ spinel refractory in contact with high $\mathrm{MnO}$ slag. Ceramics International, 43, 15074-15079. doi: 10.1016/ j.ceramint.2017.08.034

46. Huang A., Wang Y., et al. (2018): Dynamic interaction of refractory and molten steel: Corrosion mechanism of alumina-magnesia castables. Ceramics International, 44, 14617-14624. doi: 10.1016/j.ceramint.2018.05.085

47. Han J. S., Kang J. G., et al. (2018): Influence of $\mathrm{CaF}_{2}$ in calcium aluminate-based slag on the degradation of magnesia refractory. Ceramics International, 44, 19197-13204. doi: 10.1016/j.ceramint.2018.04.145

48. Huang A., Wang Y., et al. (2018): Dynamic interaction of refractory and molten steel: Effect of alumina-magnesia castables on alloy steel cleanness. Ceramics International, 44, 22146-22153. doi: 10.1016/j.ceramint.2018.08.327

49. Zou Y., Gu H., et al. (2017): Effects of aggregate microstructure on slag resistance of lightweight $\mathrm{Al}_{2} \mathrm{O}_{3}-\mathrm{MgO}$ castable. Ceramics International, 43, 16495-16501. doi: 10.1016/j.ceramint.2017.09.033

50. Luz A. P., Leite F. C., et al. (2013): Slag conditioning effects on $\mathrm{MgO}-\mathrm{C}$ refractory corrosion performance. Ceramics International, 39, 7507-7515. doi: 10.1016/j.ceramint.2013. 03.001
51. Chen L., Malfliet A., et al. (2016): Comparison of the chemical corrosion resistance of magnesia-based refractories by stainless steel making slags under vacuum conditions. Ceramics International, 42, 743-751. doi: 10.1016/ j.ceramint.2015.08.175

52. Park J. S., Kim D. H., Park J. H. (2015): Thermodynamic stability of spinel phase at the interface between alumina refractory and $\mathrm{CaO}-\mathrm{CaF}_{2}-\mathrm{SiO}_{2}-\mathrm{Al}_{2} \mathrm{O}_{3}-\mathrm{MgO}-\mathrm{MnO}$ Slags. Journal of the American Ceramic Society, 98, 1974-1981. doi: $10.1111 /$ jace. 13570

53. Chen S.-K., Cheng M.-Y., et al. (2002): Thermal characteristics of $\mathrm{Al}_{2} \mathrm{O}_{3}-\mathrm{MgO}$ and $\mathrm{Al}_{2} \mathrm{O}_{3}$-spinel castables for steel ladles. Ceramics International, 28, 811-817. doi: 10.1016/ S0272-8842(02)00047-0

54. Ko Y.-H. and Ko Y.-C. (1983): Simulated service test of torpedo ladle brick. American Ceramic Society Bulletin, 62, 1010-1012.

55. Ko Y.-C. (2002): Role of spinel composition in the slag resistance of $\mathrm{Al}_{2} \mathrm{O}_{3}$-spinel and $\mathrm{Al}_{2} \mathrm{O}_{3}-\mathrm{MgO}$ castables. Ceramics International, 28, 805-810. doi: 10.1016/S02728842(02)00046-9

56. Korgul P., Wilson D. R., Lee W. E. (1997): Microstructural analysis of corroded alumina-spinel castable refractories. Journal of the European Ceramic Society, 17, 77-84. doi: 10.1016/S0955-2219(96)00073-8

57. Hon M.-H., Hsu C.-C., Wang M.-C. (2008): Corrosion of magnesia-chrome brick in molten $\mathrm{MgO}-\mathrm{Al}_{2} \mathrm{O}_{3}-\mathrm{SiO}_{2}-$ $\mathrm{CaO}-\mathrm{FetO}$ slag. Materials Chemistry and Physics, 110, 247-255. doi: 10.1016/j.matchemphys.2008.02.001

58. Zhang S., Lee W. E. (2001): Influence of additives on corrosion resistance and corroded microstructures of $\mathrm{MgO}-\mathrm{C}$ refractories. Journal of the European Ceramic Society, 21, 2393-2405. doi: 10.1016/S09552219(01)00208-4

59. Bavand-Vandchali M., Golestani-Fard F., Sarpoolaky H. (2008): The influence of in situ spinel formation on microstructure and phase evolution of $\mathrm{MgO}-\mathrm{C}$ refractories. Journal of the European Ceramic Society, 28, 563-569. doi: 10.1016/j.jeurceramsoc.2007.07.009 